\title{
CONVERSACIÓN EN LA FACULTAD DE ARQUITECTURA CON ANTONIO FERNÁNDEZ ALBA
}

$\mathrm{H}$ ACE DOS AÑos, Antonio Fernández Alba visitó Argentina y en su viaje incluyó un paso por Mar del Plarencias y mantuvo una suerte de «reportaje» público de más de dos horas, de cuyo heterogéneo y apasionado recorrido sobre cuestiones de una actualidad vigente da cuenta apretada la presente nota. Salmantino de origen (nacido en el 27) y madrileño de asentamiento (donde instala su estudio después de graduado en 1957 y donde también sostiene su cátedra de Elementos de Composición, en la ETSAM, desde 1970), presenta la poco peculiar condición del doble ejercicio del oficio y el pensar de la Arquitectura: ambos planos desde los cuales no pierde la oportunidad de criticar «a la española» (es decir, con furia) las flagrantes pérdidas de ética social que presenta el cuadro frívolo de una posmodernidad cuyo malévolo epicentro ubica en la producción norteamericana.

Roberto Fernández. El primero de los puntos por tratar sería, a mi juicio, aquel que se refiere a la posibilidad de una "modernidad inconclusa», en el sentido de la eventual existencia de elementos, resultados o valores de «lo moderno» que apareciesen como significativos... y luego, si esa posible valoración de lo moderno alcanza preferentemente a Europa o también a América.

Antonio Fernández Alba. Hay, creo, una confusión terminológica con la idea de «lo moderno», sobre cuáles son sus límites o fronteras. Incluso es difícil discernir si esta suerte de 
«modernidad reciclada» o última que nos es casi contemporánea, supone en sí cambios cualitativos respecto de la primera, o bien si es decididamente crítica o negativa del Movimiento Moderno. Los epígonos del primer vanguardismo han podido esgrimir una crítica al MM, en tanto poseedor de ciertos principios inacabados e inoperantes. Por lo demás, existe una idea actual de modernidad cifrada en cuestiones de ruptura de códigos lingüísticos, por la cual se desplaza el interés por lo funcional a lo simbólico. Algunas operaciones de lenguaje mantienen analogías con procedimientos de los años veinte, solo que a la tautología de la función se la ha reemplazado por la tautología del símbolo. Esa sustitución del dato funcional -antes prioritario- constituye una de la claves de la neomodernidad, en tanto actualidad mucho más frívola y carente de interés en los significados.

También habrá que decir que un rasgo de la actual modernidad es su nortedmericanización. La arquitectura norteamericana no tuvo protagonismo en la primera modernidad y solo aparecerá una atracción tardía en aspectos del funcionalismo ya en los cincuenta y los sesenta, desprovistos de intereses vanguardistas y relacionados con demandas del desarrollo capitalista. Parecería que la arquitectura de Estados Unidos tiende a recuperar el tiempo perdido y va a intentar participar de un cierto protagonismo en la recuperación de la escena urbana, lo que parece un hecho político-cultural de la sociedad americana tanto como una necesidad del desarrollo de su economía. Hay así, necesidades simbólicas en la estructura material, tanto como una intención de corporizar «ideologías», procesos en los que la arquitectura recuperará allí ciertos restos «clásicos» de su funcionamiento histórico: ese papel relativamente olvidado es recuperado digamos en el período 1950I970. Pero lo que aparenta ser un proceso positivo quedará tergiversado en una virtual neutralización de las potencias críticas de las vanguardias, al aparecer dominantemente el principio de autoridad de lo monopólico, que sitúa la eventual recuperación de la arquitectura al servicio acrítico del puro desarrollo del capitalismo. Lo mismo podrá advertirse en el campo del arte americano, lejos de procesos de recuperación de su pujanza crítica, como por caso en el neoxpresionismo alemán. Pero, lo cierto es que en el contexto de una expansión 
notable del mundo de lo comunicacional, la arquitectura de EE. UU. se instalará, aunque espuriamente, en la recuperación de cierta funcionalidad simbólica.

R. F. Siguiendo con tu línea discursiva, parecería que habría alguna positividad en la neomodernidad (o sea: en la actual condición posmoderna), aunque tergiversada en la naturaleza del propio desarrollo capitalista. Pero volviendo atrás, entonces, ¿sería posible sostener algunas críticas respecto del Movimiento Moderno?

A. F. A. Quizás lo más criticable de la experiencia del MM haya que cargárselo a su debilidad institucional, a su incapacidad de dejar una herencia insoslayable de lo que significó su carga ética y moral, o sea, en suma, su perfil político-cultural. Se aprovechó poco lo que supuso la ascesis de la abstracción, subsumido por el desarrollo capitalista en versiones caricaturescas, al estereotiparse el lenguaje de la arquitectura racionalista. Habría un verdadero despojamiento de atributos en cómo el epigonismo barrió toda connotación ético-moral.

Ese despojamiento crea el actual vacío conceptual, la presente carencia de valores, ideas o principios. Queda, por ejemplo, una cierta traducción remanente del MM, solo situable en la manipulación plástica, en el uso de instrumentos compositivos al nivel del proyecto, pero quedó marginada la cuestión de lo constructivo, de la concreción real y material de lo concebido en el plano simbólico.

R. F. ¿Lo dicho permitiría que indagásemos la cuestión global de un cierto fracaso de la arquitectura como disciplina social, en la actualidad? Es decir, no puede hoy parecer que existen cambios impopulares tanto en la producción (tendiente a la especialización e introspección del metalenguaje) y en el consumo (cada vez más circunscrito a «amateurs») de la arquitectura? ¿No crees, poniendo un ejemplo, que la popularidad cultural y la fortuna productiva de un Otto Wagner hoy están definitivamente perdidas?

A. F. A. Por una parte, una merma de la vigencia productiva de la arquitectura debe atribuirse al desarrollo de nuestras sociedades, a los cambios estructurales y superestructurales del capitalismo. Pero, por otra parte, y dentro de aquello que parecería posible que dependa de nuestra propia capacidad de control y autocrítica, existe ciertamente una confusión en el 
plano de lo lingüístico. Es curioso que hoy podamos advertir un gran desarrollo de la teoría y la historiografía que se apoya en la técnica de la producción del lenguaje, antes que en los aspectos referentes a la recepción o consumación de la comunicación y los mensajes. Hay un interés central en los significantes, en los factores constitutivos del discurso y, por otra parte, un notorio desinterés en los significados, en el contenido narrativo o discursivo de los mensajes o textos. En esa enfatización de lo referente a la sintaxis de los significantes es que hay que ubicar el interés específico de lo posmoderno y, a la vez, ello explica su frivolidad, su falta de ambición en indagar sobre la naturaleza de la recepción o lectura de dichos significantes, lo que conllevaría a una preocupación por los mensajes o los significados. La consecuencia es una virtual destrucción del lenguaje, una polisemia en la cual crecen los dogmatismos autoritarios tendentes a fijar unos códigos mínimos dentro de la infernal proliferación de ruidos de lenguaje. Yo encuentro en ello, por otra parte, una de las explicaciones referentes al manejo casi exclusivamente abstracto de los significantes, sin mayor preocupación por el sentido constructivo, material, de esas referencias: un recurso como la doble fachada es visualizable así, como un elemento puramente ideológico, abstracto y ajeno a la fenomenología real de su construcción y uso o experiencia-fruición.

La polisemia afecta por igual a espacios y artefactos, emerge como una verdadera característica cultural, exacerbada además por la uniformidad creciente de las comunicaciones, operadas centralmente. En tal universo de homogeneización, los objetos quedan como neutros. No hay pasión o poesía ninguna: los discursos, al desemantizarse, se desarrollan en derredor de ciertas figuras retóricas, como la perífrasis, el tropos, la metonimia, etc. Naturalmente, esto lleva a una de las explicaciones sobre la introspección de estos discursos, el profundo bermetismo iniciático de los mismos, tanto en su producción como en su consumo. Pero otra explicación adicional o complementaria, sería el creciente narcisismo de los productores, los cuales tienden a hacer prevalecer datos de sus propias biografías azarosas o truculentas: esta adjetivación narcisista, propia de un repertorio anecdotista se puede ver con toda claridad en la obra de Philip Johnson, legítimamente uno de los pocos personajes de cover 
stories. La consecuencia de estos procesos de desemantización y de autorreferencialidad, será la conversión del lenguaje en metalenguaje, que por otra parte se relaciona en la transformación de la relación moderna entre espacios y objetos, entendibles como mercancías. En efecto, ahora, se tratará de metamercancías. No hay valor real en su materialidad, los aspectos concretos de la producción, el material, el trabajo, quedan anulados, subsumidos o descalificados en la importancia central de su rendimiento lingǘstico y en el puro placer de las tautologías.

La sintesis histórica entre la razón constructiva y la razón compositiva-que creo que es la condición histórica y epistemológica de la arquitectura como disciplina- se ha roto y aparece una unidimensionalidad metalingiística, especialmente turbadora. Incluso, vuelvo a decirlo, operaciones como la formulación de arquetipos intenta ser, desde el seno de lo metalinguísti$\mathrm{co}$, un esfuerzo de ordenar autoritariamente la comunicación, inexorablemente polisémica. Estos cambios que verificamos, a través de la teoría de la Arquitectura, en el espacio, se dan análogamente en el mundo de los objetos industriales, en los que también crece un desinterés por el consumo efectivo o placentero de los mismos, además de una voluntad de tipificación metalingüística e impositiva.

$\mathbb{R}$. $\mathbb{F}$. De tu discurso se desprende una suerte de autocomplacencia del nuevo rol que cumplirían las vanguardias actuales, si es que existen, aun cuando parecen perder aceleradamente importancia cultural y productiva, por ejemplo, en las relaciones con dirigentes políticos o con promotores de obras, relaciones ambas bastante aceitadas en la primera modernidad, por ejemplo en Gropius o en Le Corbusier.

A. F. A. Efectivamente, esto no puede ser visto más que como un retroceso histórico, como una dificultad creciente en cumplir con funciones históricamente asumidas por la disciplina que obligaban, por así decirlo, a sus ejecutantes a cumplir ciertas instancias de relación socioproductiva. Hoy, dicha autocomplacencia, que se parece a la mecánica interna del desarrollo de la moda, bloquea los términos de adecuadas relaciones sociales. Pero, además, me gustaría aludir a un cierto problema de conocimiento que presente este estado de nuestra disciplina, cuyas diferencias respecto de la ciencia hoy son ya abismales: la ciencia presenta hoy un estado de duda creativa 
que sigue relacionándose, a mi juicio, con una cierta confianza en la razón, la cual, por otra parte, permitió corregir y criticar los excesos del propio desarrollo científico. La pérdida aparente del favor de la arquitectura por dicho interés científico en lo racional, y por el contrario su entrega a una pura fruición de la operación metalingüística, expresaría una medida de la degradación del conocimiento arquitectónico, e indirectamente de su inserción social. La pérdida de protagonismo podría, por otro lado, verificarse en la disminución del rol de la arquitectura en la función artística, respecto de la cual los viejos ideales de integración atribuidos, desde el Renacimiento, a la arquitectura, hoy parecen definitivamente perdidos. Hay, además, comparado con el desarrollo de otras expresiones artísticas, una gran puerilidad de la actual arquitectura en cuanto al cumplimiento de sus funciones artísticas, lo que a mi juicio debe ser atribuido a la escasa producción ensayística, crítica, teórica. Las artes se sostienen y desarrollan merced a un trabajo teórico-crítico expansivo, no introspectivo. Debe constar también, apuntaría aquí, una disminución de la importancia del pensamiento utópico, no como un pensamiento del no-lugar sino como una atención preferente a la relevancia de la prefiguración, entendida como capacidad crítica o progresiva. Esta neutralización de la función utópica, entendida en su dimensión social e ideológica, se conecta con este avance de la autorreferencialidad que antes señalábamos, con este desarrollo de las «arquitecturas de autor», con referencias biográficas, oníricas, tendentes a una autonarración que vulnera cualquier efecto de generalidad, cualquier tentativa de impacto en la cultura social. Por lo demás, el tiempo que otrora suponía la gestión de un proyecto hoy parece haber sido transferido a las actividades propias de la promoción, o la autopromoción, con lo que conlleva en disminución del tiempo productivo por una parte, y la disminución de la voluntad crítica por la otra: hoy los instrumentos de promoción - revistas, muestras, usos de cátedras, etc.- no pueden cumplir, parecería su función de promoción a la vez que la actividad crítica.

$\mathbb{R}$. F. ¿Esa falta de actividad crítica -o de interés en la crítica- se conectaría por una parte con el creciente peso reivindicativo de lo histórico, que parece constituirse en uno de los datos de la actividad teórica más dominantes en el panorama contemporáneo de la arquitectura? 
A. F. A. Creo que el interés supuesto por lo histórico no es un hecho relacionable con una voluntad, por así llamarla, crítica o científica, sino que es otra característica vinculable con las necesidades de esta neomodernidad. Diría que más que interés en lo histórico hay un interés en la nostalgia, una cierta preocupación en el recuerdo nostálgico. Ahora, creo que la práctica de la nostalgia es lo opuesto a la práctica científica de la historia. La tendencia melancólica respecto de un cierto pasado elaborado como material nostálgico, no solo encubre la realidad del pasado, el cual se angula en una interpretación selectiva y complaciente, sino que tiende a fundamentar el eludir la critica del presente, que es lo que no se puede sostener. Por otro lado, la realidad de los Estados Unidos supone virtualmente la inexistencia de bistoria como una concreta y consciente acumulación de tiempo. Allí, por ser lo actual lo permanente, el pasado se asume como presente, y como es un pasado «débil» tiende a ser enaltecido con las técnicas de la nostalgia. Lo histórico aparece más bien -en su real inconsistencia, o en su externidad, si se trata de la historia de otros, por ejemplo la europea-como un contexto, un trasfondo justificativo de la idea de cambio rápido, de eterno volver al comienzo: si lo presente es lo suficientemente excitante y multifacético, el pasado es nada más que una cantera nostálgica de referencias y el futuro es nada más que un presente apenas por delante. Hay, así, no solo una falta de espesor de lo bistórico, sino además como una falta de acumulación de verdad. De allí es que surge como una nueva ética una tendencia a la simulación, al cambio permanente. Yo encuentro en esa dimensión peculiar de la cultura contemporánea - que es el caso de Estados Unidos- una explicación a las tendencias posmodernas de la arquitectura, a la eliminación de la razón constructiva y al aval a una arquitectura montadia en la simulación de los objetos, de la historia, de las relaciones sociales.

R. F. Por cierto, es difícil «operativizar» lo histórico, hacerse cargo de los procesos históricos de los que depende el ejercicio de lo contemporáneo. Por otra parte, la fuerza de los hechos presentes, contingentes, hoy resulta avasallante, tanto por la complejidad de esos hechos como por el bombardeo de mucha información. Lo presente, hoy, entonces, aparece connotado como la condición de lo posmoderno, que, como planteaste, va desarrollando una ética y una estética. De tal contemporaneidad 
habrá hechos positivos, aceptables, vistos desde la perspectiva crítica de la «modernidad inconclusa». Hechos como la valorización -al menos teorizada- de la relación arquitectura-ciudad o del énfasis en la dimensión urbana de la arquitectura, o incluso la recuperación de cierto interés por lo estético, por lo lingüístico del discurso arquitectónico, sobre todo después de tanto énfasis sociologizante allá por los sesenta; ¿tales hechos pueden, a tu juicio, ser interpretados como positivos?

A. F. A. Respecto de la supuesta valorización -o revalorización- de lo estético del lenguaje arquitectónico ya dije que me parece un elemento fallido y que la prevalencia de elementos de simulacro, de falseamiento de la verdad histórica y social no admite ninguna consideración positiva: esa supuesta estetización es de orden necesariamente degradante, reaccionario. Es cierto que cuestiones como la crítica a un rígido hiperfuncionalismo que pudo desarrollarse en estas épocas presentes puede verse como un rasgo positivo, pero el avance de la fuerza «pos-» del simulacro, de la mentira nos eriza especialmente: si la simulación es una constante, no bay valores posibles. ¿Hasta dónde puede llegar una supuesta recuperación de lo estético o de lo urbano sin verdad? También es cierto, y aquí vuelvo a deslindar responsabilidades de la institución arquitectónica respecto de la totalidad social, que una sociedad tal como la presente, con tanto desarrollo de tecnología, es francamente irracional que preste tanta atención, tantos recursos a lo frívolo, a lo simulatorio. Hago un parangón con la medicina: se trata, por caso, que la sociedad resuelva priorizar los tratamientos de estética facial o corporal antes que la lucha contra el cáncer; sería como una decisión social insólita y contradictoria, tanto respecto de la tecnología disponible como de las necesidades sociales y su atención priorizada. Y bien, esta incongruencia creo que existe al nivel de la arquitectura, y, por cierto, raya en la injusticia y la crueldad. Algunas cosas o elementos pueden suponer la necesidad de una supuesta superación a nivel estético o formal, pero en el contexto de la sociedad contemporánea se trata de un muy débil valor, si acaso lo sea.

R. F. En definitiva, parecería deducirse que el creciente peso por lo estético, según tu planteamiento, sería básicamente un vehículo de simulación o encubrimiento de la realidad, o de ciertas relaciones de producción y de poder... 
Por cierto, existe una teoria del «como si», de lo simulatorio, en la cual el hecho de un renovado interés en lo estético o en lo urbano no es un valor en sí mismo, sino más bien una manifestación de las limitaciones o falseamientos de la verdad crítica. Por otra parte, hay hechos que solo superficialmente admitirían un reconocimiento positivo, por ejemplo lo que llamaría un contextualismo perverso, una voluntad reproductiva de ciertos elementos tipológicos operantes en la realidad urbana, pero que en rigor son, diría, elementos malos, aunque posean una cierta densidad histórica. Que no es tampoco el caso americano, donde una intención filológica en lo tipológico no logra superar la simulación de una concepción teatral de la arquitectura urbana, donde el concepto de arquitecturización urbana no puede trascender una mera disposición de telones. Esas ideas tipológicas que suelen, a manera de soporte teórico, funcionar como fundamentos de operaciones proyectuales, no dejan de tener el talante de mentiras piadosas, precarias condiciones para sostener una verdad operativa incongruente con la verdad social. Ciertos referentes de esa arquitectura del tipo contextualita perverso puede que sean reales (o existentes), pero no dejan de ser sinies" tros: como las cárceles, los cementerios, los laberintos; esos gestos de hieráticas geometrías que tan bien acompañan las «necesidades» introspectivas y metalingüísticas de lo muerto y francamente en este momento expansivo de la cultura - por ejemplo, en las artes plásticas- estos juegos de embalsamadores parecen cosas que deberían enterrarse definitivamente.

A. F. A. La crítica efectiva de algunas formas de producción actual del diseño nos puede conducir a comprobaciones patéticas: pareciera, por ejemplo, que lo máximo a que puede aspirar la arquitectura de hoy - viendo los fastos de Olimpíadas-, es crear escenarios decorativos como aquel de la coronación de Carlos III. Ello a pesar de que, como en el caso del pabellón de Barcelona del 29, los arquitectos intentan combatir lo efímero mediante el sinsentido de una «mascarada perenne», valga la metáfora, en un stand de acero y hormigón, aunque tampoco ello le garantizó, desde luego, la permanencia. A hora bien, frente a todo ello y de cara al futuro, ¿qué es lo que hay que hacer, reproducir o contraproducir en el ámbito de una escuela de Arquitectura? Es decir, si es que la profesión, por la vía de esa proliferación de gestos vacuos y escenográficos parece 
entrar en una suerte de callejón sin salida, ¿no habrá, desde las escuelas, que promover, estimular y generar los necesarios cambios epistemológicos necesarios para recuperar la atención de necesidades sociales?

Totalmente de acuerdo. Habría que refundar las prácticas de la arquitectura, usando el conocimiento real proveniente de las distintas ciencias. La arquitectura de tipo introspectivo constituye un reduccionismo demasiado dócil a una división del trabajo situada en lo omnipresente de un capitalismo mercantilista. Lo efímero en arquitectura constituye una forma de encerramiento en las condiciones de mediación que los tiempos de las necesidades políticas crean para esta arquitectura de lo efímero, que es una forma más de los mass media. Encerrarse en tales límites no supone opción alguna para la arquitectura; será preciso plantear como escisiones o frentes de desarrollo alternativo para la arquitectura.

R. F. En esta cuestión de ver hacia adelante, hacia lo que puede encerrar un futuro disciplinar para la arquitectura, ha sido a veces resuelto (o mal resuelto) mediante una apelación a la autoridad de lo histórico, apoyándose en la supuesta tranquilidad de statu quo. En ese sentido, siempre me pareció interesante una frase de Pesce, un diseñador italiano, quien decía que así como el presente (de la arquitectura) debe respetar el pasado, también el pasado debe respetar el presente, en el sentido de no desresponsabilizar la acción presente de su propio compromiso histórico. A partir de esa responsabilidad, ¿se pueden superar o enriquecer esas posturas contextualistas que no trascienden la cuestión formal?

A. F. A. El contextualismo que llamaste formal pudo tener algún resultado de interés, dependiendo desde luego, del talento del arquitecto involucrado. Pero no puede haber un mero contextualismo de tipo estilístico, cosmético. Un verdadero contextualismo, para ir en búsqueda de variantes antropológicas, sociales, debe intentar situarse en la real dimensión de unos espacios históricos: no puede haber un puro contextualismo espacial o formal, sino que debe haber, si se quiere, un contextualismo bistórico, de inserción en el tiempo de los procesos sociales, culturales e históricos. Personalmente, si bien encuentro positivo a nivel cultural una determinada acumulación o densidad bistórica del habitar, no tengo un interés especial en la reconstrucción de tal 
contextualismo histórico, que puede recaer en juegos demasiado arqueológicos o eruditos. Pero está claro que la idea de contexto es como un dato de proyecto, es como estar en un texto, como situar un párrafo, un discurso, una palabra, en una determinada urdimbre significacional. Siendo así, lo contextual sería una cuestión inherente al propio proceso de proyecto, tratándose de insertar a este en la temática del lugar. Lo moderno, forzando singularidades o diferencias respecto de este texto dado de un sitio o lugar, pudo inducir a alguna violencia proyectual, en el sentido antedicho de hacer vulnerable al estar en un texto.

R. F. Por cierto, ya cerrando esta conversación y luego de tu nueva venida a América, que se suma a la experiencia de varios otros viajes, ¿qué te sugieren para estas cuestiones de teoría y crítica de arquitectura que hemos estado tratando, las problemáticas americanas, el vacío de algunos territorios, la escala peculiar de algunos ámbitos urbanos, la insuficiencia de equipamientos básicos, el peso de eso que se ha ido denominando "ciudad informal»?

A. F. A. Hay muy distintas Américas, por empezar con algo: esas ideas totalizadoras, como América Latina o como Tercer Mundo, suelen encubrir estrategias colonizadoras, aplanamientos de la complejidad, homogeneizaciones. Hay países, como Argentina, Chile, México, Colombia, que tienen una cierta tradición cultural y una producción relativamente autónoma, basada en su propio desarrollo, dicho esto sin dejar de considerar sus cuadros particulares de dependencia económica, etc. Argentina, en particular Buenos Aires, tuvo un liderazgo, algún peso en la elaboración de la modernidad que diría, incluso, fue ejemplar para España durante nuestras décadas obscuras. Habría que referir analogías entre Argentina y España; países del tipo «vertedero cultural», sitios no de productores, sino de gentes ávidas de modernización y de información. Esa cualidad a veces no depende de la fortuna del desarrollo económico: si bien un desarrollo no significativo ha obstruido aquí las posibilidades del despliegue material de la arquitectura, es bastante sorprendente la ejemplaridad con que se manejaron ciertas tipologías, como el skyscraper, del cual el Kavanagh es un espléndido resultado. Por otro lado, aquí es ostensible el peso de la cultura, de la arquitectura de alusiones, del gran efecto de un Le Corbusier; o antes, de los repertorios eclécticos. 
Pero no generalicemos; a mi juicio, el caso de Buenos Aires es extremadamente atípico en el contexto latinoamericano. Como también parecen serlo muchos de sus arquitectos. Otras ciudades, como Bogotá, parecen tener mayor identidad, han ido desarrollándose como más idénticas a si mismas, antes que a referencias externas. Y también, por dar otro ejemplo latinoamericano, Luis Barragán quizás sea representativo de una posible manera de trabajar en la complejidad latinoamericana, con un modesto y reducido código (dos o tres colores, pocas formas de muros, etc.), una especie de Pedro Páramo a nivel arquitectónico.

Otro comentario que haría respecto a mi experiencia en América es el de las diferencias que encuentro con la escala, con las dimensiones, por ejemplo, en la idea de calle. Las calles en América -o el espacio público, en general- me parecen diferentes a la de la tradición europea, ámbitos en los que emerge la idea de un espacio americano, que tal vez, en parte, sea una mezcla de la historia de la ciudad europea junto a algunos impactos de la tecnología norteamericana. Es difícil en estos ambientes urbanos encontrar persistencias tipológicas o arquetípicas, la identidad puede que pase por el estudio de la escala, de los límites, de las dimensiones, y luego de los usos y sus sentidos, de los mitos y los ritos... La clave de esa identidad, en todo caso, será la diversidad antes que la repetición de lo único, de lo tipológico.

Respecto de la idea de metrópolis débiles, como sería el caso de Lima, encuentro alguna imprecisión terminológica. A mi entender no se trataría de «metrópolis», sino de aglomeraciones, sitios que conjugan, en un tiempo histórico, quizás no dilatado, y un territorio determinado, varios asentamientos superpuestos, que no logran configurar una condición de complejidad metropolitana, aunque sean muy grandes, físicamente hablando. No diría que son «débiles», creo más bien que son como patologías urbanas o metropolitanas en las que hasta resultan difíciles los diagnósticos y luego, las terapias. Ha habido, respecto de estas patologías, demasiadas lecturas o intentos de explicación de tipo político o social; y poca tendencia a enfrentarlos desde un punto de vista científico. Tanto la ciencia urbana como la arquitectura - sacada esta de sus reclusiones e introspecciones europeas o sus juegos perversos norteamericanos- deberían acogerse, con mayor plan científico, al estudio de vuestras ciudades: Lima o México son, así creo, los laboratorios más relevantes para transformar, de cara 
al futuro, las aptitudes concretas de nuestras disciplinas. En los próximos años, aunque quizás no se den cuenta con precisión, tendrán por aquí los escenarios más comprometidos con el futuro de este oficio de la arquitectura.

CASI TODA LA ESCRITURA DE A. F. A. -desperdigada por periódicos, revistas y varios libros- es de alegato, en el sentido del reclamo de una moral perdida en un mundo de cruda mercantilización y diverso oportunismo. En la mejor tradición ensayística (la de Loos, Kraus o Cioran), este texto es una colección de mazazos, dados contra la frivolidad postmodern: «El hombre de hoy vive en territorios de desencanto. Habita espacios y soporta moradas construidas sin proyecto de lugar, recorre la ciudad sin identificación posible y su biografía discurre alrededor de un vacío miserable» (pp. I4-I 5 ). Lo que es credo de una estética de la degradación, para Fernández Alba, conforma la carne de un desértico paisaje, en el sentido de aquella inhospitalidad que ya Heidegger había advertido en cierta tergiversación abstractizante de lo moderno, que por cierto se hace decididamente trágica en la circunstancia posmoderna que el pensador de Friburgo no alcanzó a conocer.

Los 5 textos del trabajo (cuyos títulos, de por sí ilustrativos, son: «La arquitectura humillada», «El inconcluso epigrama de la modernidad en arquitectura», "De la arquitectura en la ciudad del siglo XXI», «El espacio del presente en el pasado», «El ornamento de los caballeros», más la «Fábula a modo de epílogo», «Delito y estuco (Las mariposas de Rockefeller Center)», así como el denso texto presentativo de E. Subirats («La Arquitectura en una edad de transición»), no se agotan en puras letanías apocalípticas, sino que esgrimen el talante crítico a modo de intento de recuperación de una ética perdida. Una ética que Subirats todavía radica en una arquitectura que sea capaz de constituirse en el lugar privilegiado de la producción y representación de cultura. Para Fernández Alba, por otra parte, la crítica arriba a comentarios bien precisos sobre la crisis de la proyectación, en la que cada vez más se confiere importancia a lo bidimensional (planta y fachadas) en detrimento de la conceptualización del espacio y la manipulación justa de las secciones: lo cual conduce a advertir, 
en la crisis de la arquitectura postmodern, la crisis derivada de una creciente pérdida de interés en lo constructivo, en la factura real de los espacios arquitectónicos. «Proyectos - nos dice nuestro autor- surgidos en el laboratorio de las formas, sin relación posible entre paisaje y construcción, cultura y naturaleza, bombre yambiente» (p. 83): una vez más, la alusión a equilibrios perdidos sustenta en Fernández Alba la referencia crítica a rupturas entre tales dialécticas que lo posmoderno esgrime como valores.

También queda elocuentemente presentada una defensa a aquellas cuestiones que la modernidad no terminó de desarrollar y que acaso sigan suponiendo adecuados horizontes utópicos para una tensión positivamente ética del valor social de la arquitectura: por ejemplo, la potencia que, de la polaridad composición/cons. trucción, devendría en caminos apenas insinuados por la modernidad «heroica» y que todavía constituyen firmes campos de modernidad no consumada: la articulación de la construcción con la industria, la relación de la tecnología y la naturaleza.

La falta creciente del sentido de constructividad, la pérdida de la idea de lugar, son también cuestiones propias de la crítica a la crítica posmoderna de la modernidad: es decir, una crítica a la complacencia en la representación antes que en la presentación, en el simulacro antes que en la realidad, en la reproducción antes que la producción.

Estas tendencias antimodernas, ligadas a la renuncia a la capacidad de cuestionamiento cultural del proyecto moderno en tanto creación de cultura, estarán, por último, plenamente manifiestas en las actuales ideas regresivas acerca de la ciudad. «El futuro de la ciudad, su construcción y formalización, no reside ya en la interpretación del pasado, como soñaban algunos de los arquitectos menos radicales de los años veinte, ni en el análisis crítico de la ideología del espacio urbano, al que se entregaron con fervorosa adhesión sociólogos, economistas y gestores municipales en los años sesenta y setenta. Ahora las propuestas vienen por un itinerario más simplificado: la ciudad y su arquitectura deben imitar el pasado, ya sea este próximo o remoto» (p.93). Testimonio de un militante del tablero y de la cátedra, el libro merece ser leído a la luz de esas experiencias, confrontándoselo con lo real de una producción proyectual que, sobre todo, en los ámbitos periféricos, parece saturada de las discutibles neutralidades de puros formalismos. 